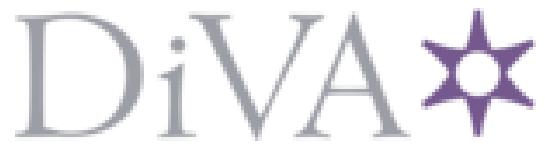

http://www.diva-portal.org

This is the published version of a paper published in Energy \& Fuels.

Citation for the original published paper (version of record):

Liu, T., Li, G., Shen, N., Ahlquist, M S., Sun, L. (2021)

Hydrophobic Interactions of Ru-bda-Type Catalysts for Promoting Water Oxidation Activity

Energy \& Fuels, : acs.energyfuels.1c02097

https://doi.org/10.1021/acs.energyfuels.1c02097

Access to the published version may require subscription.

N.B. When citing this work, cite the original published paper.

Permanent link to this version:

http://urn.kb.se/resolve?urn=urn:nbn:se:kth:diva-302711 


\title{
Hydrophobic Interactions of Ru-bda-Type Catalysts for Promoting Water Oxidation Activity
}

\author{
Tianqi Liu, ${ }^{\dagger}$ Ge Li, ${ }^{\dagger}$ Nannan Shen, Mårten S. G. Ahlquist, and Licheng Sun* \\ Cite This: https://doi.org/10.1021/acs.energyfuels.1c02097 \\ Read Online
}

ABSTRACT: The catalytic activity of the bimolecular reaction was affected by many parameters. Although many efforts have been dedicated to investigate the influence of secondary interactions in pre-organizing catalysts, the hydrophobic effect on Ru-bda-type water oxidation catalysts remains unclear as a result of the lack of an ideal catalytic model. In this work, four catalysts $\mathbf{1 - 4}$ with variable hydrophobicity have been synthesized, and cerium(IV)-driven water oxidation results showed that the hydrophobic complexes 3 and 4 outperformed the hydrophilic complex 2 . Steric mapping, nuclear magnetic resonance, and differential pulse voltammogram studies indicated that the increase in activity has no correlation with electronic and steric effects but has correlation with hydrophobicity. Molecular dynamics have shown that the modifications of the hydrophobicity on the axial pyridine ligands of the Ru-bda type of catalysts can improve the water oxidation catalytic activity by stabilizing the pre-reactive catalyst dimer.

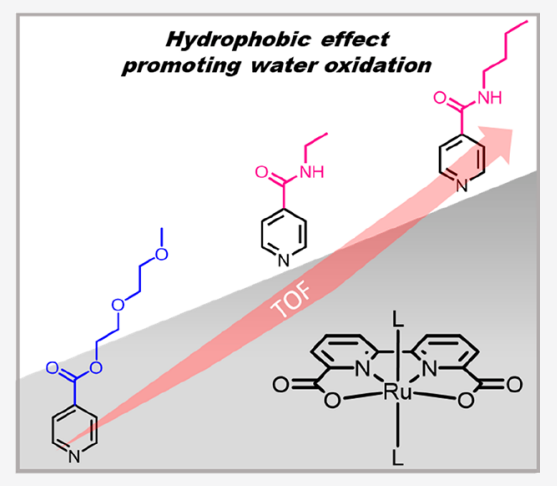

\section{INTRODUCTION}

Photosynthesis, using solar energy to convert water and carbon dioxide into oxygen and carbohydrate molecules, has powered nearly all life forms on the Earth for billions of years. Inspired by nature, splitting water into oxygen and hydrogen as a fuel via artificial photosynthesis has become a popular topic and potentially solves the energy shortage problem. As one of the half-reactions, however, water oxidation suffers uphill thermodynamics and sluggish kinetics as a result of the four proton and four electron transfer involved. To this end, the development of efficient water oxidation catalysts accompanied by a comprehensive mechanism understanding is highly needed. Two kinds of $\mathrm{O}-\mathrm{O}$ bond formation mechanisms have been proposed in water oxidation reactions: single-site water nucleophilic attack (WNA) and double-site radical coupling (also known as the interaction of two metal-oxo entities, I2M). ${ }^{1,2}$ Catalysts undergoing the latter pathway have theoretically lower overpotential according to the scaling relationships because it avoids the formation of the highenergy metal-OOH intermediates. ${ }^{3}$ The state-of-the-art molecular water oxidation catalyst reported thus far is the $\mathrm{Ru}$-bda-type catalyst, which contains the step of coupling two $\mathrm{Ru}^{\mathrm{V}}=\mathrm{O}$ species (or $\mathrm{Ru}^{\mathrm{IV}}-\mathrm{O}^{\bullet}$ ) during $\mathrm{O}-\mathrm{O}$ bond formation. Because two reactive units are involved in the catalytic cycle, the turnover frequency (TOF) of Ru-bda-type catalysts is concentration-dependent, which allows for reaching high activities through increasing the catalyst loading amount. ${ }^{4}$ On the other hand, this also limits the application at lower concentrations.

Supramolecular strategies could alleviate this paradox in two ways: covalent linking monomeric catalyst or pre-organizing two monomeric units non-covalently at an appropriate distance. ${ }^{5,6} \mathrm{Di}-$, $^{7,8}$ tri-, $^{9-13}$ and tetra-nuclear ${ }^{14}$ Ru-bda-based water oxidation catalysts have been synthesized and showed increased activities, indicating the reliability of the strategy. However, considering the complexity of the synthesis of multinuclear structures, non-covalent assembly strategies seem more attractive. Many reported works have emphasized the role of secondary interactions in intercatalyst coupling, as shown in Figure 1, such as $\pi-\pi$ interaction, ${ }^{15,16}$ electrostatic interaction, ${ }^{17}$ off-set interaction, ${ }^{18}$ etc. We envisage that those non-covalent interactions between the axial ligands can be expanded to hydrophobic interactions by replacing the substituents of axial ligands. The promotional effects of hydrophobicity have been found in iridium- and cobalt-based molecular water oxidation catalysis experimentally, and recent calculation results also indicated that hydrophobic/hydrophilic directionality determined the catalytic pathways in rutheniumbased catalysts. ${ }^{19-21}$ Our group has previously evaluated the hydrophobic effects using $\left(\mathrm{CH}_{2}\right)_{3} \mathrm{Ph}$-substituted pyridine as axial ligands; however, the cerium(IV)-driven water oxidation activity was not as high as expected as a result of the poor solubility. $^{22}$ Therefore, the clear structure-activity relationship of hydrophobic effects remains unresolved.

Special Issue: 2021 Pioneers in Energy Research:

Vivian Yam

Received: June 25, 2021

Revised: July 12, 2021 
<smiles></smiles>

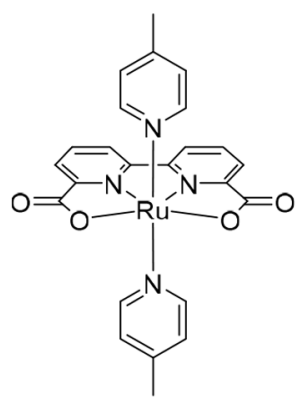

1

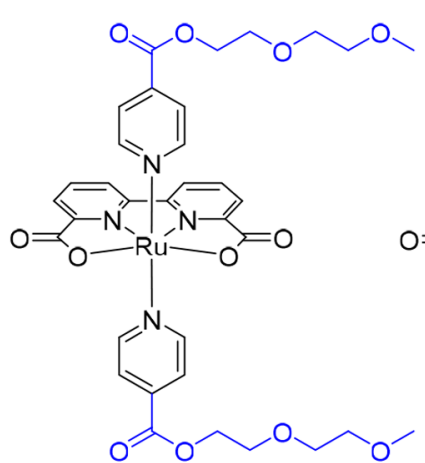

2

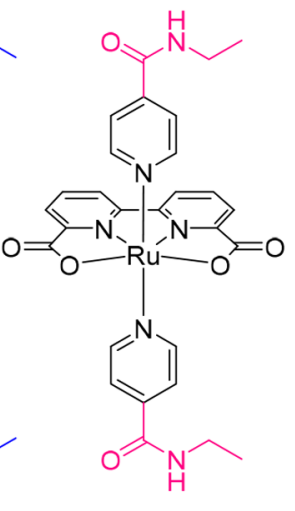

3

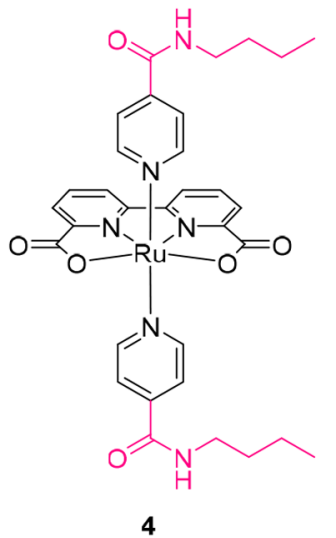

4

maximizing hydrophobic effect

minimizing changes in the electronic/steric effects

Figure 1. (Top) Axial ligands that have been investigated in previous studies for promoting water oxidation performances and (bottom) molecular structures of complexes 1-4 studied in this work.

Despite the central role of secondary interactions in boosting bimolecular $\mathrm{O}-\mathrm{O}$ bond formation, rational comparison of the hydrophobic effects also needs to exclude other factors, such as steric and electronic effects. We proposed that the ideal modifications on axial ligand require (1) avoiding using charged ligands to minimize electrostatic repulsions, (2) avoiding using meta-substituted ligands to minimize steric interactions, (3) avoiding using $\pi$-extended ligands to minimize $\pi-\pi$ interaction, and (4) maximizing the hydrophobic effect while maintaining the first three points. In this work, we selected the facile available para-substituted pyridines with a glycol chain and hydrophobic alkyl chains as axial ligands to comprehend the hydrophobic effects in Ru-bda-type water oxidation catalysts.

\section{EXPERIMENTAL SECTION}

Synthesis and Characterization. Complex 1 was synthesized via a modified literature procedure. ${ }^{23}$ In comparison to reference molecule 1, complex 2 contains the hydrophilic axial ligands and complexes 3 and $\mathbf{4}$ contain the hydrophobic axial ligands. Complexes 2-4 were prepared by procedures similar to complex 1, i.e., refluxing a degassed mixture of $\left[\mathrm{Ru}(\mathrm{bda})(\mathrm{DMSO})_{2}\right]$ and the axial ligand in methanol under $\mathrm{N}_{2}$. The desired complexes were isolated through column chromatography and characterized by ${ }^{1} \mathrm{H}$ and ${ }^{13} \mathrm{C}$ nuclear magnetic resonance (NMR) and high-resolution mass spectrometry (HR-MS) (Figures $\mathrm{S} 1-\mathrm{S} 3$ of the Supporting Information). Complex 2: ${ }^{1} \mathrm{H}$ NMR (500 MHz, MeOD), $\delta 8.66(\mathrm{~d}, J=7.4 \mathrm{~Hz}, 2 \mathrm{H}), 8.09$ (d, $J$ $=6.7 \mathrm{~Hz}, 4 \mathrm{H}), 8.04(\mathrm{~d}, J=7.6 \mathrm{~Hz}, 2 \mathrm{H}), 7.96(\mathrm{t}, J=7.9 \mathrm{~Hz}, 2 \mathrm{H}), 7.72$ $(\mathrm{d}, J=6.7 \mathrm{~Hz}, 4 \mathrm{H}), 4.44-4.40(\mathrm{~m}, 4 \mathrm{H}), 3.78-3.74(\mathrm{~m}, 4 \mathrm{H}), 3.64-$ $3.59(\mathrm{~m}, 4 \mathrm{H}), 3.49(\mathrm{dd}, J=6.2$ and $3.0 \mathrm{~Hz}, 4 \mathrm{H}), 3.29(\mathrm{~s}, 6 \mathrm{H}) ;{ }^{13} \mathrm{C}$ NMR (126 MHz, MeOD), $\delta 165.11,161.12,157.27,154.67,153.41$, $139.05,134.21,127.38,126.82,125.05,72.95,71.42,69.85,66.29$, 59.25; HR-MS calculated for $\mathrm{C}_{34} \mathrm{H}_{36} \mathrm{~N}_{4} \mathrm{O}_{12} \mathrm{Ru}^{+}\left[\mathrm{M}+\mathrm{H}^{+}\right]^{+}$, 795.1446; found, 795.1455. Complex 3: ${ }^{1} \mathrm{H}$ NMR (500 MHz, MeOD), $\delta 8.67$ $(\mathrm{d}, J=8.1 \mathrm{~Hz}, 2 \mathrm{H}), 8.04(\mathrm{~d}, J=7.1 \mathrm{~Hz}, 2 \mathrm{H}), 8.02(\mathrm{~d}, J=6.8 \mathrm{~Hz}, 4 \mathrm{H})$, 7.99-7.94 (m, 2H), $7.54(\mathrm{~d}, J=6.8 \mathrm{~Hz}, 4 \mathrm{H}), 3.35-3.32(\mathrm{~m}, 4 \mathrm{H})$, $1.16(\mathrm{t}, J=7.3 \mathrm{~Hz}, 6 \mathrm{H}) ;{ }^{13} \mathrm{C}$ NMR (126 MHz, MeOD), $\delta 174.99$, $166.17,161.19,157.38,154.21,143.40,134.11,127.44,126.79$, 123.61, 36.19, 14.75; HR-MS calculated for $\mathrm{C}_{28} \mathrm{H}_{26} \mathrm{~N}_{6} \mathrm{O}_{6} \mathrm{Ru}^{+}[\mathrm{M}+$ $\left.\mathrm{H}^{+}\right]^{+}$, 645.1043; found, 645.1049. Complex 4: ${ }^{1} \mathrm{H}$ NMR (500 MHz, MeOD), $\delta 8.68(\mathrm{~d}, J=8.0 \mathrm{~Hz}, 2 \mathrm{H}), 8.04(\mathrm{~d}, J=7.6 \mathrm{~Hz}, 2 \mathrm{H}), 8.02(\mathrm{~d}$, $J=6.7 \mathrm{~Hz}, 4 \mathrm{H}), 7.97(\mathrm{t}, J=7.9 \mathrm{~Hz}, 2 \mathrm{H}), 7.53(\mathrm{~d}, J=6.7 \mathrm{~Hz}, 4 \mathrm{H})$, $3.35(\mathrm{~s}, 4 \mathrm{H}), 1.52(\mathrm{~m}, 4 \mathrm{H}), 1.37-1.32(\mathrm{~m}, 4 \mathrm{H}), 0.92(\mathrm{t}, J=7.4 \mathrm{~Hz}$, $6 \mathrm{H}) ;{ }^{13} \mathrm{C}$ NMR (126 MHz, MeOD), $\delta 175.00,166.33,161.19$, $157.38,154.21,143.45,134.14,127.45,126.89,123.63,41.08,32.34$, 21.17, 14.25; HR-MS calculated for $\mathrm{C}_{32} \mathrm{H}_{34} \mathrm{~N}_{6} \mathrm{O}_{6} \mathrm{RuNa}^{+}\left[\mathrm{M}+\mathrm{Na}^{+}\right]^{+}$, 723.1490; found, 723.1491.

Physical Methods. ${ }^{1} \mathrm{H}$ and ${ }^{13} \mathrm{C}$ NMR spectra of the compounds were recorded with a Bruker Avance DMX 500 NMR spectrometer. HR-MS measurements were performed at the Dalian University of Technology and Westlake University. Differential pulse voltammetry measurements were carried out with a CHI660c potentiostat with glassy carbon as the working electrode and $\mathrm{Pt}$ wire as the auxiliary electrode and measured versus $\mathrm{Ag} / \mathrm{AgCl}$ as the reference electrode. All potentials reported herein are converted to their corresponding values versus normal hydrogen electrode (NHE). An Omega PXM409 pressure transducer was used to monitor the $\mathrm{Ce}^{\mathrm{IV}}$-driven water oxidation activities.

The single-crystal diffraction data were measured at $277 \mathrm{~K}$ using Mo $\mathrm{K} \alpha(\lambda=0.71073 \AA)$ radiation on a Bruker D8 VENTURE singlecrystal X-ray diffractometer equipped with a kappa geometry goniometer. The data set was reduced, and absorption correction was applied in APEX3 suite. The crystal structure was solved and refined by SHELXL-2018 and OLEX2, respectively. ${ }^{24}$ The crystal structure was refined using full-matrix least squares based on $F^{2}$ with all non-hydrogen atoms anisotropically defined. The hydrogen atoms were located at geometrically calculated positions. A summary of the crystallographic data (CCDC deposition number 2091346), the data 
collection parameters, and the refinement parameters are given in Table S1 of the Supporting Information.

Computational Details. Complexes 2-4 were optimized by density functional theory (DFT) using the Jaguar 10.3 program package by Schrödinger, LLC. ${ }^{25}$ The functional and basis set for structral optimizations were B3LYP-D $3^{26-29}$ and LACVP**,30 respectively. Coordinates of the optimized structures of complexes 2-4 are provided in the Supporting Information. The frequency calculations for optimized complexes $2-4$ were performed to verify that the geometries correspond to the energetic minima. After geometry optimization at the DFT level, a procedure used in our recent publications has been used to prepare topology files of complexes 2-4 for molecular dynamics (MD) simulations. ${ }^{31}$ Force field parameters of the $\mathrm{Ru}^{\mathrm{V}}(\mathrm{O})$ bda fragment for the new complexes were adopted from previous work, ${ }^{31}$ and the bonded and van der Waals parameters for different axial ligands were complemented with standard all-atom optimized potentials for liquid simulations (OPLSAA) parameters. ${ }^{32}$ Atomic partial charge parameters were calculated in an iterative way to compute an average electrostatic potential (ESP) charge by taking 20 conformations from short MD calculations with an initial charge distribution. By calculating of the ESP charges of the different conformations and taking the average of those charges, we reassigned the atomic charges to the new force field.

The GROMACS 2019.6 software package was used for all MD simulations. ${ }^{33}$ The simulation system was a cubic box of an initial size of $6.0 \mathrm{~nm}$ containing a $\mathrm{Ru}^{\mathrm{V}}(\mathrm{O}) \mathrm{bda}$ dimer of different species, two chloride ions to neutralize the system, and $\mathrm{SPC} / \mathrm{E}^{34}$ water molecules to fill the rest of the box. First, 100000 steps of steepest descent minimization were performed. The Verlet cutoff scheme ${ }^{35}$ was used, and the particle mesh Ewald (PME) ${ }^{36}$ method was employed to obtain accurate evaluation of the long-range electrostatic interactions beyond the cutoff. Second, canonical ensemble $(N V T)$ simulations of $100 \mathrm{ps}$ were performed by heating the system to $300 \mathrm{~K}$ with a vrescale $^{37}$ thermostat. Thereafter, the isothermal isobaric ensemble $(N P T)$ simulations were conducted for 100 ps at 1 bar pressure with a v-rescale thermostat and Parrinello-Rahman ${ }^{38}$ barostat. During the $N V T$ and NPT simulations, the linear constraint solver (LINCS) ${ }^{39}$ algorithm was used to constrain all of the bond lengths. A time step of $1 \mathrm{fs}$ was used for the whole simulation.

Potential of mean force (PMF) analysis was performed on complex 2-4 dimers using the umbrella sampling method. ${ }^{40}$ Energy minimization and NVT and NPT ensemble calculations were conducted in the same way as above. The two groups of each dimer were pushed together to estimate the binding energy between the two monomers when centers of mass of them are from a long distance of around $2 \mathrm{~nm}$ to a short distance of around $0.5 \mathrm{~nm}$. The distance range was then increased because there were still interactions between two monomers with longer axial ligands, even though they were far away from each other. The spring constant and rate are 2000 $\mathrm{kJ} \mathrm{mol}^{-1} \mathrm{~nm}^{-2}$ and $0.001 \mathrm{~nm} \mathrm{ps}^{-1}$, respectively. A total of 32 umbrella sampling windows were generated on the basis of the configurations of snapshots from the previous trajectory with $0.5 \AA$ spacing. A 100 ps equilibration and a $10 \mathrm{~ns} \mathrm{MD}$ simulation in the NPT ensemble for each window with a total simulation time of $320 \mathrm{~ns}$ were further performed to obtain the binding energies between two monomers with the weighted histogram analysis method (WHAM). ${ }^{41}$

\section{RESULTS AND DISCUSSION}

Crystal Structure and Packing. A single crystal of complex 3 was obtained by slow diffusion of diethyl ether into a methanolic solution of complex 3 at room temperature. Complex 3 features a distorted octahedral coordination configuration with an $\mathrm{O}-\mathrm{Ru}-\mathrm{O}$ angle of $122.24^{\circ}$ and a N$\mathrm{Ru}-\mathrm{N}$ angle of $168.72^{\circ}$, which are typical for Ru-bda-type complexes. ${ }^{23}$ Two Ru molecules are included in a unit cell, as presented in Figure 2, where the distances between hydrophobic chains and axial aromatic rings are in the range of 3.5$4.5 \AA$ A. Similar distances were found in the crystal structures

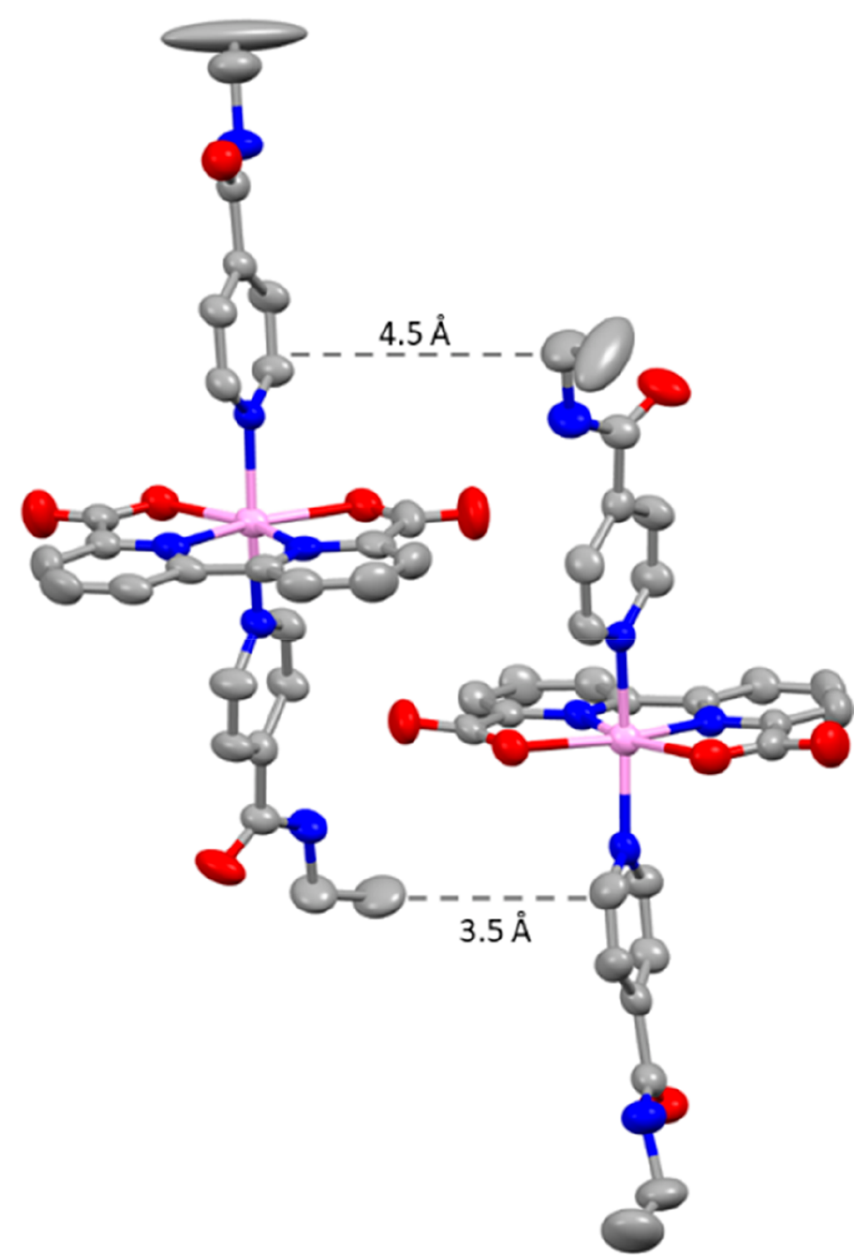

Figure 2. Single-crystal structure of complex 3 with thermal ellipsoids at $50 \%$ probability. Hydrogen atoms and solvent molecules are omitted for clarity.

containing a larger $\pi$ system (with isoquinoline as axial ligands), ${ }^{16}$ suggesting that $\mathrm{CH}-\pi$ interactions ${ }^{18,42}$ may also play an important role in the formation of the pre-reactive dimer. $^{43}$

Water Oxidation. To compare the hydrophobic effects of axial ligands on catalytic activities, chemical-driven water oxidation was carried out using cerium(IV) as the oxidant in acidic aqueous solution. As shown in Figure 3, all of the modifications on axial ligands make the catalysts more active than the parent complex 1 under the same given conditions, and the corresponding initial TOFs of complexes $\mathbf{1 - 4}$ were 22, 81,118 , and $146 \mathrm{~s}^{-1}$, respectively. As expected, the activities of hydrophobic alkyl-chain-modified catalysts 3 and $\mathbf{4}$ outperform those of catalyst $\mathbf{1}$ and hydrophilic glycol-chain-tailed catalyst 2, validating the hypothesis that the hydrophobic effect of the axial ligands plays a substantial role in pre-organizing two catalytic units. Complex 2 with hydrophilic substituents showed better performance than complex 1, possibly as a result of the electro-withdrawing effects of the substituents on axial ligands. For a fair comparison of the impact of the hydrophobic effect, it is necessary to exclude the impact of the hindrance and electronic effect on the catalytic performance.

Hindrance Effect. A previous report showed that the electrostatic hindrance raised by negatively charged sulfonate groups hindered bimolecular coupling reactions. ${ }^{22}$ Therefore, in this study, neutral ligands were selected to avoid 

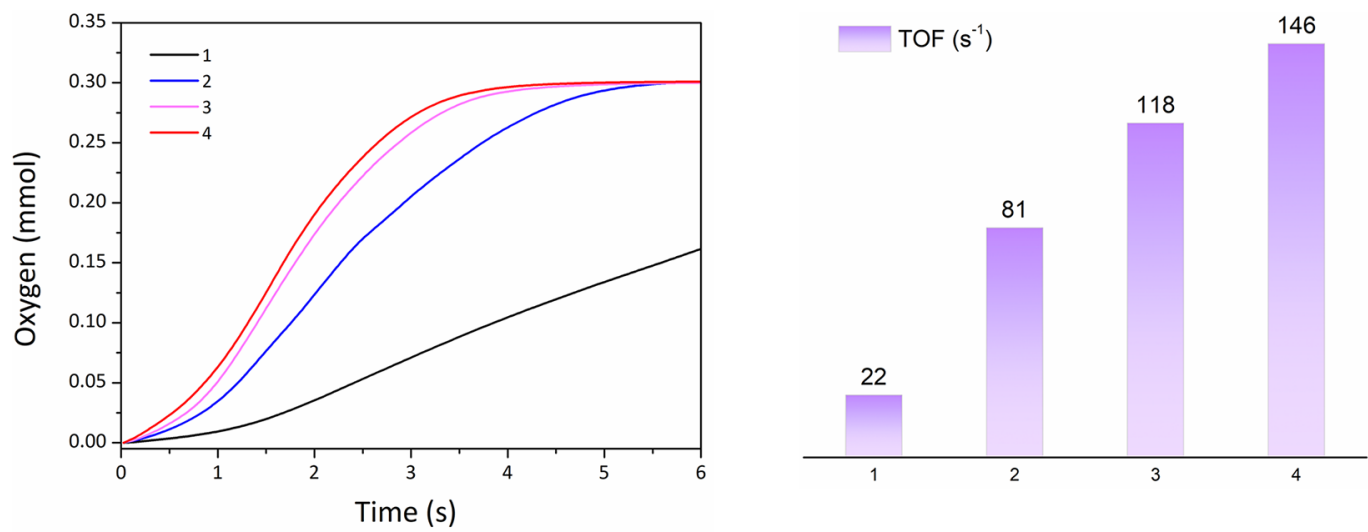

Figure 3. Kinetic plots of oxygen evolution by complexes 1-4 versus time and corresponding TOF values in 1:10 $\mathrm{CF}_{3} \mathrm{CH}_{2} \mathrm{OH} / \mathrm{water}(\mathrm{pH}$; acid, trifluoromethanesulfonic acid), $\mathrm{Ce}^{\mathrm{IV}}=1.2 \mathrm{mmol}$, and [Cat $]=100 \mu \mathrm{M}$.

electrostatic repulsion effects. In addition, steric hindrance may also influence the available catalytic surface that the ligands offer to the substrate/terminal oxygen atoms from other catalysts. For instance, using small axial ligands [dimethyl sulfoxide (DMSO) and imidazole] could increase the TOFs. ${ }^{44}$ Topographic steric mapping ${ }^{45-47}$ was used here as a descriptor to check if the modifications on the para position of axial ligands affect the catalyst-substrate interaction. As shown in Figure 4, the positive values indicate zones where the ligand protrudes toward the reactants, thus limiting the disposal space thereof. Complexes $\mathbf{1}$ and $\mathbf{3}$ share similar topographic steric maps, suggesting that it is reasonable to use the modified catalyst to prove the hydrophobic effect. It is worth noting that

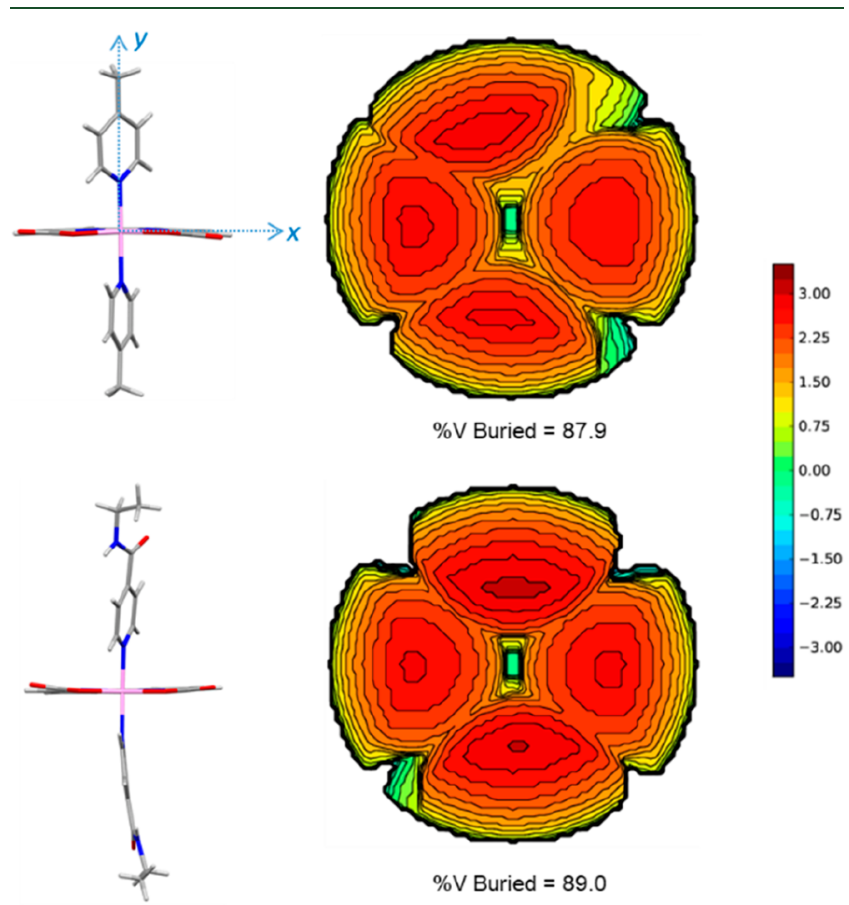

Figure 4. Topographic steric maps for (top) complex 1 and (bottom) complex 3 calculated from their X-ray structures ${ }^{23}$ using SambVca 2.1. Both equatorial and axial ligands were considered in the calculation of the percentage of buried volume. The steric maps are viewed down the $z$ axis, which bisects the $\mathrm{O}-\mathrm{Ru}-\mathrm{O}$ angle. The isocontour scheme is shown in angstroms. This figure was reproduced with permission from ref 23. Copyright 2009 American Chemical Society. the data for calculating the steric maps come from the singlecrystal structures, in which the catalytic center is wrapped by axial and equatorial ligands. Therefore, the vicinity of the catalytic center appears to be highly hindered for both complexes 1 and 3 . In the actual homogeneous catalysis solution, however, the axial ligand can rotate freely to expose the $\mathrm{Ru}$ site, thereby increasing the chance of contact between the reactant and the catalytic center.

Electronic Effect. The electron-rich ligand could lower the oxidative potential of $\mathrm{Ru}^{\mathrm{IV} / \mathrm{V}}$ to lower the onset potential of water oxidation, while the electron-deficient ligand could destabilize $\mathrm{Ru}^{\mathrm{V}}$ to enhance its reactivity. The promotional effect of electro-withdrawing substituents has been observed by the Sun group; ${ }^{22}$ however, Murata and co-workers obtained the completely opposite result. ${ }^{48}$ Because the bimolecular coupling reaction is a complicated process, it is unclear whether electronic effects are dominant in catalysis. Because catalysts 1-4 bear different substituent groups and chains of various lengths, it is necessary to take the impact of the electronic effect on the catalytic performance into consideration.

Two parameters, i.e., chemical shifts and $\mathrm{Ru}^{\mathrm{III} / \mathrm{II}}$ redox potentials, were used here to reflect the electro-withdrawing abilities of substituents. The protons in the vicinity of an electro-withdrawing group experience reduced electron density; therefore, those protons were deshielded and showed larger chemical shifts. It is found that the order of the electrowithdrawing ability of the substituents is $2>3=4>1$ by comparing the chemical shifts of $\mathrm{H}_{\mathrm{e}}$ in ${ }^{1} \mathrm{H}$ NMR spectra of complexes 1-4 (Figure 5a), indicating no clear correlation between electronic effects and the catalytic water oxidation activities (TOFs of $\mathbf{4}>\mathbf{3}>\mathbf{2}>\mathbf{1}$; Figure 5c in magenta). Redox potentials of $\mathrm{Ru}^{\mathrm{III} / \mathrm{II}}$ were also affected by the electronic nature of axial ligands, showing the same electro-withdrawing trend $(2>3=4>1$; panels $b$ and $c$ of Figure 5 in blue). Those results confirmed that electronic effects were not the only factor influencing the catalytic activity and the secondary interaction may have a greater impact.

Hydrophobic Effect. Because the hindrance and electronic effects have been ruled out, the only possible parameter is the secondary interaction. There are three key steps determining the overall catalytic performance in the $\mathrm{O}-\mathrm{O}$ bond formation, which are the diffusion of two monomer catalysts in the water, the formation of the preactive dimer by the collision, and the $\mathrm{O}-\mathrm{O}$ bond formation. Complex $\mathbf{1}$ has been shown to form the 


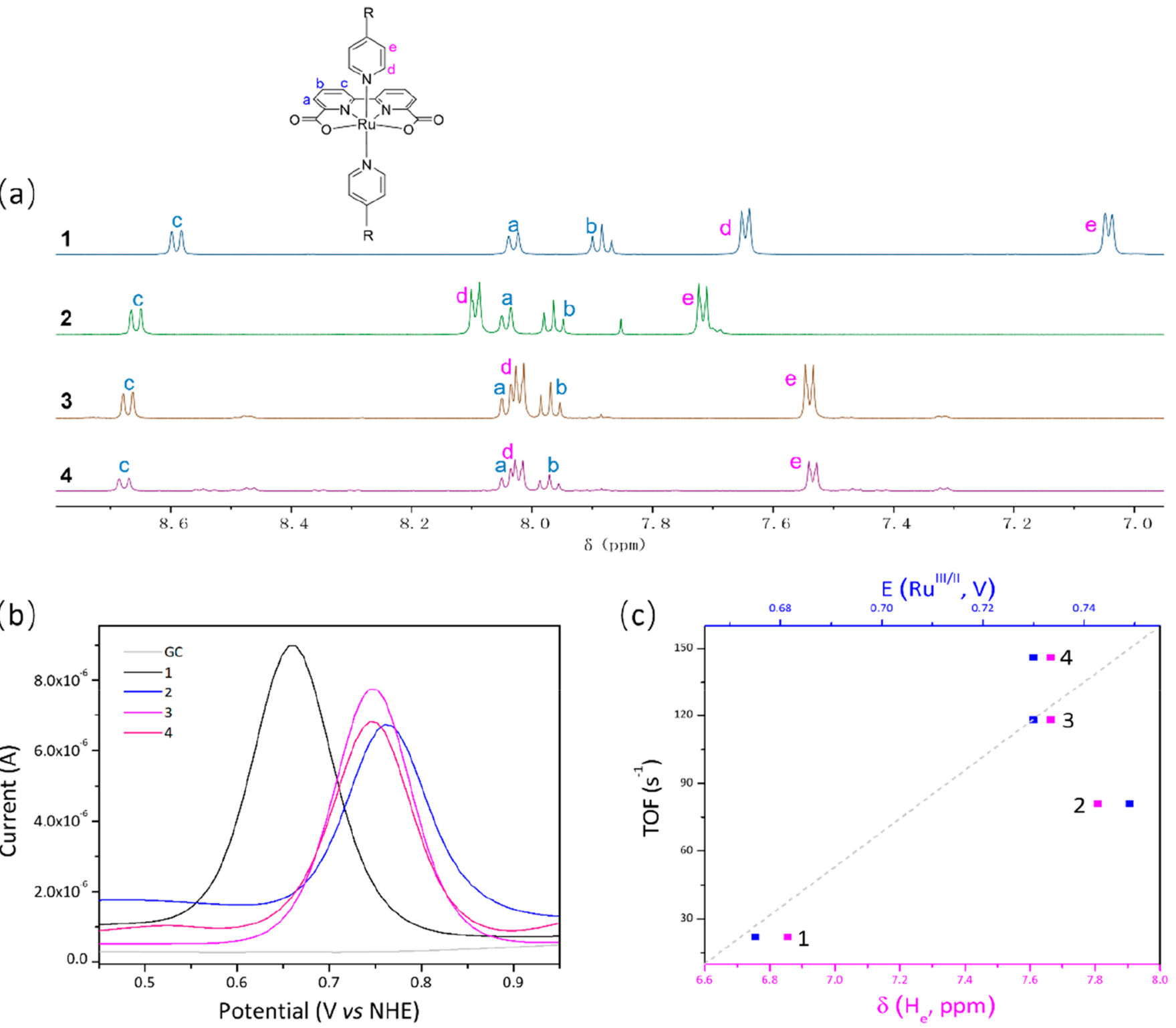

Figure 5. (a) ${ }^{1} \mathrm{H}$ NMR spectra of complexes 1-4 in MeOD, (b) differential pulse voltammograms of complexes 1-4, and (c) correlation of TOFs with chemical shifts of $\mathrm{H}_{\mathrm{e}}$ (magenta) and redox potentials of $\mathrm{Ru}{ }^{\mathrm{III} / \mathrm{II}}$ (blue).

$\mathrm{O}-\mathrm{O}$ bond via the bimolecular radical coupling mechanism, and thereby, it is rational to assume that complexes $2-4$ will interact similarly given that the modifications of the ligands are only situated on the axial pyridine ligands. ${ }^{43}$ In addition, previous studies have shown that, for the Ru-bda type of water oxidation catalysts (for example, $\left.[\mathrm{Ru}(\mathrm{bda}) \text { (picoline) })_{2}\right]$ and $\left.\left.[\mathrm{Ru}(\mathrm{bda}) \text { (isoquinoline })_{2}\right]\right)$, the activation free energies of $\mathrm{O}-$ $\mathrm{O}$ bond formation are very similar and that the main determinant for the rate is the binding free energies of dimers relative to the free monomers. ${ }^{43}$ Consequently, the binding free energies of complex 2-4 dimers from around 2 to $0.5 \mathrm{~nm}$ were computed by calculation of the potential of mean force using the umbrella sampling method. Figure 6 showed that the binding free energies of complexes 2,3 , and 4 were -3.46 , -3.78 , and $-3.90 \mathrm{kcal} \mathrm{mol}^{-1}$, respectively, which are all more negative than that of complex 1, at $-3.20 \mathrm{kcal} \mathrm{mol}^{-1}$ from our previous study. ${ }^{43}$ The differences were very subtle, but both the trend and the relative binding free energies match very well with the differences in the values of the TOF of complexes 2-
4. In detail, the difference in TOF between complexes 3 and 4 corresponds to a difference in activation energy of merely 0.13 $\mathrm{kcal} \mathrm{mol}{ }^{-1}$ based on the Arrhenius equation. For complexes 2 and 3 , the difference in TOF corresponds to the activation free energy difference of $0.22 \mathrm{kcal} \mathrm{mol}^{-1}$. It is also noteworthy that the interaction between two monomers completely vanishes for complex 1 when the distance of them is beyond $9.5 \AA \AA^{43}$ while there is still an interaction for complex 2-4 dimers from over 9.5 to around $16.0 \AA$. The long-distance interaction can be attributed to the long-chain ligands in complexes 2-4. While it has not been evaluated in more detail here, it could affect the radius of the complexes, which, in turn, could affect the collision frequency. The larger radius could increase the chance of collision as a result of the larger collision areas; however, it could also slow the diffusion rate and finally lead to a small net result. 


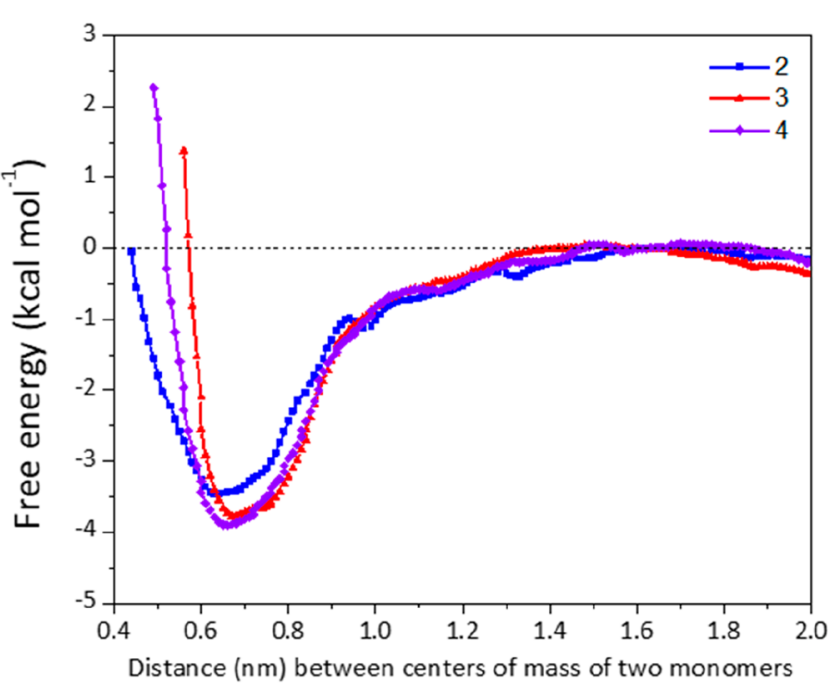

Figure 6. Free energy profiles of complex 2-4 dimers against distances between centers of mass of two monomers.

\section{CONCLUSION}

After elimination of the influence of electronic and hindrance effects, a clear structure-activity relationship of the hydrophobic effect was established through rational comparison of water oxidation performances of complexes 1-4. MD simulations support that the hydrophobic modifications on the axial ligands can promote the water oxidation catalytic efficiency by strengthening the binding of two free monomers, especially for complex 4 with longer hydrophobic ligands. This effect may have possible applications in the field of other types of cooperative catalysis.

\section{ASSOCIATED CONTENT}

\section{SI Supporting Information}

The Supporting Information is available free of charge at https://pubs.acs.org/doi/10.1021/acs.energyfuels.1c02097.

${ }^{1} \mathrm{H}$ and ${ }^{13} \mathrm{C}$ NMR and HR-MS spectra and umbrella sampling histograms of complexes 2-4, summary of the crystallographic data for complex 3 , and $x y z$ coordinates used for calculations (PDF)

Crystallographic information file (CIF)

\section{AUTHOR INFORMATION}

\section{Corresponding Author}

Licheng Sun - Department of Chemistry, School of Engineering Sciences in Chemistry, Biotechnology and Health, KTH Royal Institute of Technology, 10044 Stockholm, Sweden; State Key Laboratory of Fine Chemicals, Dalian University of Technology (DUT), Dalian, Liaoning 116024, People's Republic of China; Center of Artificial Photosynthesis for Solar Fuels, School of Science, Westlake University, Hangzhou, Zhejiang 310024, People's Republic of China; 자이.org/0000-0002-4521-2870; Email: lichengs@ kth.se

\section{Authors}

Tianqi Liu - Department of Chemistry, School of Engineering Sciences in Chemistry, Biotechnology and Health, KTH Royal Institute of Technology, 10044 Stockholm, Sweden; (1) orcid.org/0000-0002-0672-9965
Ge Li - Department of Theoretical Chemistry \& Biology, School of Engineering Sciences in Chemistry, Biotechnology and Health, KTH Royal Institute of Technology, 10691 Stockholm, Sweden

Nannan Shen - State Key Laboratory of Radiation Medicine and Protection, School for Radiological and Interdisciplinary Sciences (RAD-X) and Collaborative Innovation Center of Radiation Medicine of Jiangsu Higher Education Institutions, Soochow University, Suzhou, Jiangsu 215123, People's Republic of China

Mårten S. G. Ahlquist - Department of Theoretical Chemistry \& Biology, School of Engineering Sciences in Chemistry, Biotechnology and Health, KTH Royal Institute of Technology, 10691 Stockholm, Sweden; 이이.org/00000002-1553-4027

Complete contact information is available at: https://pubs.acs.org/10.1021/acs.energyfuels.1c02097

\section{Author Contributions}

†Tianqi Liu and Ge Li contributed equally to this work.

\section{Notes}

The authors declare no competing financial interest.

\section{ACKNOWLEDGMENTS}

All of the calculations were performed using computing resources of Projects SNIC 2021/5-42 and SNIC 2021/6-18 on the National Supercomputer Center (NSC, Linköping University) and SNIC 2020/5-647 on the PDC Center for High Performance Computing (KTH Royal Institute of Technology) provided by the Swedish National Infrastructure for Computing (SNIC). The authors acknowledge the Diamond Light Source for access to beamline I19 (MT20805). This work was financially supported by the Swedish Research Council (2017-00935), the Knut and Alice Wallenberg Foundation (KAW 2016.0072), and the China Scholarship Council (CSC). The author thanks Dr. Yinjuan Chen from the Instrumentation and Service Center for Molecular Sciences at Westlake University and Prof. Fusheng Li from DUT for the assistance in HR-MS measurement.

\section{REFERENCES}

(1) Zhang, X.-P.; Wang, H.-Y.; Zheng, H.; Zhang, W.; Cao, R. O-O bond formation mechanisms during the oxygen evolution reaction over synthetic molecular catalysts. Chin. J. Catal. 2021, 42 (8), 12531268.

(2) Shaffer, D. W.; Xie, Y.; Concepcion, J. J. O-O bond formation in ruthenium-catalyzed water oxidation: Single-site nucleophilic attack vs. O-O radical coupling. Chem. Soc. Rev. 2017, 46 (20), 6170-6193.

(3) Hessels, J.; Detz, R. J.; Koper, M. T. M.; Reek, J. N. H. Rational Design Rules for Molecular Water Oxidation Catalysts based on Scaling Relationships. Chem. - Eur. J. 2017, 23 (65), 16413-16418.

(4) Zhan, S.; Ahlquist, M. S. G. Dynamics and Reactions of Molecular Ru Catalysts at Carbon Nanotube-Water Interfaces. J. Am. Chem. Soc. 2018, 140 (24), 7498-7503.

(5) Kunz, V.; Schmidt, D.; Röhr, M. I. S.; Mitrić, R.; Würthner, F. Supramolecular Approaches to Improve the Performance of Ruthenium-Based Water Oxidation Catalysts. Adv. Energy Mater. 2017, 7 (16), 1602939.

(6) Keijer, T.; Bouwens, T.; Hessels, J.; Reek, J. N. H. Supramolecular strategies in artificial photosynthesis. Chem. Sci. 2021, 12 (1), 50-70.

(7) Jiang, Y.; Li, F.; Zhang, B.; Li, X.; Wang, X.; Huang, F.; Sun, L. Promoting the Activity of Catalysts for the Oxidation of Water with 
Bridged Dinuclear Ruthenium Complexes. Angew. Chem., Int. Ed. 2013, 52 (12), 3398-3401.

(8) Noll, N.; Würthner, F. A Calix[4]arene-Based Cyclic Dinuclear Ruthenium Complex for Light-Driven Catalytic Water Oxidation. Chem. - Eur. J. 2021, 27 (1), 444-450.

(9) Schulze, M.; Kunz, V.; Frischmann, P. D.; Würthner, F. A supramolecular ruthenium macrocycle with high catalytic activity for water oxidation that mechanistically mimics photosystem II. Nat. Chem. 2016, 8 (6), 576.

(10) Kunz, V.; Lindner, J. O.; Schulze, M.; Röhr, M. I.; Schmidt, D.; Mitrić, R.; Würthner, F. Cooperative water oxidation catalysis in a series of trinuclear metallosupramolecular ruthenium macrocycles. Energy Environ. Sci. 2017, 10 (10), 2137-2153.

(11) Kunz, V.; Schulze, M.; Schmidt, D.; Würthner, F. Trinuclear ruthenium macrocycles: Toward supramolecular water oxidation catalysis in pure water. ACS Energy Lett. 2017, 2 (2), 288-293.

(12) Zhang, L. L.; Gao, Y.; Liu, Z.; Ding, X.; Yu, Z.; Sun, L. C. A trinuclear ruthenium complex as a highly efficient molecular catalyst for water oxidation. Dalton Trans. 2016, 45 (9), 3814-3819.

(13) Meza-Chincha, A.-L.; Lindner, J. O.; Schindler, D.; Schmidt, D.; Krause, A.-M.; Röhr, M. I. S.; Mitric, R.; Würthner, F. Impact of substituents on molecular properties and catalytic activities of trinuclear $\mathrm{Ru}$ macrocycles in water oxidation. Chem. Sci. 2020, 11 (29), 7654-7664.

(14) Schindler, D.; Meza-Chincha, A.-L.; Roth, M.; Würthner, F. Structure-Activity Relationship for Di- up to Tetranuclear Macrocyclic Ruthenium Catalysts in Homogeneous Water Oxidation. Chem. - Eur. J. 2021, DOI: 10.1002/chem.202100549.

(15) Duan, L.; Bozoglian, F.; Mandal, S.; Stewart, B.; Privalov, T.; Llobet, A.; Sun, L. A molecular ruthenium catalyst with wateroxidation activity comparable to that of photosystem II. Nat. Chem. 2012, 4 (5), 418-423.

(16) Richmond, C. J.; Matheu, R.; Poater, A.; Falivene, L.; BenetBuchholz, J.; Sala, X.; Cavallo, L.; Llobet, A. Supramolecular Water Oxidation with Ru-bda-Based Catalysts. Chem. - Eur. J. 2014, 20 (52), $17282-17286$.

(17) Yi, J.; Zhan, S.; Chen, L.; Tian, Q.; Wang, N.; Li, J.; Xu, W.; Zhang, B.; Ahlquist, M. S. G. Electrostatic Interactions Accelerating Water Oxidation Catalysis via Intercatalyst $\mathrm{O}-\mathrm{O}$ Coupling. J. Am. Chem. Soc. 2021, 143 (6), 2484-2490.

(18) Sun, L.; Timmer, B.; Kravchenko, O.; Liu, T.; Zhang, B. Off-set Interactions of Ru-bda Type Catalysts for Promoting Water Splitting Performance. Angew. Chem., Int. Ed. 2021, 60 (26), 14504-14511.

(19) Corbucci, I.; Petronilho, A.; Müller-Bunz, H.; Rocchigiani, L.; Albrecht, M.; Macchioni, A. Substantial Improvement of PyridineCarbene Iridium Water Oxidation Catalysts by a Simple Methyl-toOctyl Substitution. ACS Catal. 2015, 5 (5), 2714-2718.

(20) Chen, B.-T.; Morlanés, N.; Adogla, E.; Takanabe, K.; Rodionov, V. O. An Efficient and Stable Hydrophobic Molecular Cobalt Catalyst for Water Electro-oxidation at Neutral pH. ACS Catal. 2016, 6 (7), 4647-4652.

(21) Zhan, S.; Zhang, B.; Sun, L.; Ahlquist, M. S. G. Hydrophobic/ Hydrophilic Directionality Affects the Mechanism of Ru-Catalyzed Water Oxidation Reaction. ACS Catal. 2020, 10 (22), 13364-13370.

(22) Duan, L.; Wang, L.; Inge, A. K.; Fischer, A.; Zou, X.; Sun, L. Insights into Ru-Based Molecular Water Oxidation Catalysts: Electronic and Noncovalent-Interaction Effects on Their Catalytic Activities. Inorg. Chem. 2013, 52 (14), 7844-7852.

(23) Duan, L.; Fischer, A.; Xu, Y.; Sun, L. Isolated seven-coordinate $\mathrm{Ru}$ (IV) dimer complex with $[\mathrm{HOHOH}]^{-}$bridging ligand as an intermediate for catalytic water oxidation. J. Am. Chem. Soc. 2009, 131 (30), 10397-10399.

(24) Sheldrick, G. M. A short history of SHELX. Acta Crystallogr., Sect. A: Found. Crystallogr. 2008, 64 (1), 112-122.

(25) Bochevarov, A. D.; Harder, E.; Hughes, T. F.; Greenwood, J. R.; Braden, D. A.; Philipp, D. M.; Rinaldo, D.; Halls, M. D.; Zhang, J.; Friesner, R. A. Jaguar: A high-performance quantum chemistry software program with strengths in life and materials sciences. Int. J. Quantum Chem. 2013, 113 (18), 2110-2142.
(26) Becke, A. D. Density-functional thermochemistry. III. The role of exact exchange. J. Chem. Phys. 1993, 98 (7), 5648.

(27) Lee, C.; Yang, W.; Parr, R. G. Development of the ColleSalvetti correlation-energy formula into a functional of the electron density. Phys. Rev. B: Condens. Matter Mater. Phys. 1988, 37 (2), 785.

(28) Grimme, S.; Antony, J.; Ehrlich, S.; Krieg, H. A consistent and accurate $\mathrm{ab}$ initio parametrization of density functional dispersion correction (DFT-D) for the 94 elements H-Pu. J. Chem. Phys. 2010, 132 (15), 154104.

(29) Goerigk, L.; Grimme, S. A thorough benchmark of density functional methods for general main group thermochemistry, kinetics, and noncovalent interactions. Phys. Chem. Chem. Phys. 2011, 13 (14), 6670-6688.

(30) Hay, P. J.; Wadt, W. R. Ab initio effective core potentials for molecular calculations. Potentials for the transition metal atoms Sc to Hg. J. Chem. Phys. 1985, 82 (1), 270-283.

(31) Zhan, S.; Mårtensson, D.; Purg, M.; Kamerlin, S. C.; Ahlquist, M. S. Capturing the role of explicit solvent in the dimerization of $\mathrm{Ru}^{\mathrm{V}}$ (bda) water oxidation catalysts. Angew. Chem., Int. Ed. 2017, 56 (24), 6962-6965.

(32) Jorgensen, W. L.; Maxwell, D. S.; Tirado-Rives, J. Development and testing of the OPLS all-atom force field on conformational energetics and properties of organic liquids. J. Am. Chem. Soc. 1996, 118 (45), 11225-11236.

(33) Abraham, M. J.; Murtola, T.; Schulz, R.; Páll, S.; Smith, J. C.; Hess, B.; Lindahl, E. GROMACS: High performance molecular simulations through multi-level parallelism from laptops to supercomputers. SoftwareX 2015, 1-2, 19-25.

(34) Jorgensen, W. L.; Chandrasekhar, J.; Madura, J. D.; Impey, R. W.; Klein, M. L. Comparison of simple potential functions for simulating liquid water. J. Chem. Phys. 1983, 79 (2), 926-935.

(35) Páll, S.; Hess, B. A flexible algorithm for calculating pair interactions on SIMD architectures. Comput. Phys. Commun. 2013, 184 (12), 2641-2650.

(36) Essmann, U.; Perera, L.; Berkowitz, M. L.; Darden, T.; Lee, H.; Pedersen, L. G. A smooth particle mesh Ewald method. J. Chem. Phys. 1995, 103 (19), 8577-8593.

(37) Bussi, G.; Donadio, D.; Parrinello, M. Canonical sampling through velocity rescaling. J. Chem. Phys. 2007, 126 (1), 014101.

(38) Parrinello, M.; Rahman, A. Polymorphic transitions in single crystals: A new molecular dynamics method. J. Appl. Phys. 1981, 52 (12), 7182-7190.

(39) Hess, B.; Bekker, H.; Berendsen, H. J.; Fraaije, J. G. LINCS: A linear constraint solver for molecular simulations. J. Comput. Chem. 1997, 18 (12), 1463-1472.

(40) Lemkul, J. A.; Bevan, D. R. Assessing the stability of Alzheimer's amyloid protofibrils using molecular dynamics. J. Phys. Chem. B 2010, 114 (4), 1652-1660.

(41) Kumar, S.; Rosenberg, J. M.; Bouzida, D.; Swendsen, R. H.; Kollman, P. A. The weighted histogram analysis method for freeenergy calculations on biomolecules. I. The method. J. Comput. Chem. 1992, 13 (8), 1011-1021.

(42) Hoque, M. A.; Gil-Sepulcre, M.; de Aguirre, A.; Elemans, J. A. A. W.; Moonshiram, D.; Matheu, R.; Shi, Y.; Benet-Buchholz, J.; Sala, X.; Malfois, M.; Solano, E.; Lim, J.; Garzón-Manjón, A.; Scheu, C.; Lanza, M.; Maseras, F.; Gimbert-Suriñach, C.; Llobet, A. Water oxidation electrocatalysis using ruthenium coordination oligomers adsorbed on multiwalled carbon nanotubes. Nat. Chem. 2020, 12 (11), 1060-1066.

(43) Zhan, S.; Zou, R.; Ahlquist, M. S. G. Dynamics with Explicit Solvation Reveals Formation of the Prereactive Dimer as Sole Determining Factor for the Efficiency of $\mathrm{Ru}(\mathrm{bda}) \mathrm{L}_{2}$ Catalysts. ACS Catal. 2018, 8 (9), 8642-8648.

(44) Wang, L.; Duan, L.; Stewart, B.; Pu, M.; Liu, J.; Privalov, T.; Sun, L. Toward Controlling Water Oxidation Catalysis: Tunable Activity of Ruthenium Complexes with Axial Imidazole/DMSO Ligands. J. Am. Chem. Soc. 2012, 134 (45), 18868-18880. 
(45) Falivene, L.; Cao, Z.; Petta, A.; Serra, L.; Poater, A.; Oliva, R.; Scarano, V.; Cavallo, L. Towards the online computer-aided design of catalytic pockets. Nat. Chem. 2019, 11 (10), 872-879.

(46) Poater, A.; Ragone, F.; Giudice, S.; Costabile, C.; Dorta, R.; Nolan, S. P.; Cavallo, L. Thermodynamics of N-Heterocyclic Carbene Dimerization: The Balance of Sterics and Electronics. Organometallics 2008, 27 (12), 2679-2681.

(47) Poater, A.; Ragone, F.; Mariz, R.; Dorta, R.; Cavallo, L. Comparing the Enantioselective Power of Steric and Electrostatic Effects in Transition-Metal-Catalyzed Asymmetric Synthesis. Chem. Eur. J. 2010, 16 (48), 14348-14353.

(48) Sato, Y.; Takizawa, S. y.; Murata, S. Substituent effects on physical properties and catalytic activities toward water oxidation in mononuclear ruthenium complexes. Eur. J. Inorg. Chem. 2015, 2015 (33), 5495-5502. 